\title{
STUCTURAL EQUATION MODELING PARTIAL LEAST SQUARE (SEM PLS) UNTUK MENGETAHUI KINERJA KARYAWAN PADA PT. DEMPO LASER METALINDO SURABAYA
}

\author{
Aryo Wibisono ${ }^{1}$, Muhadjir Anwar ${ }^{2}$, Indro Kirono ${ }^{3}$ \\ ${ }^{1,2,3)}$ Fakultas Ekonomi, Universitas Pembangunan Nasional Surabaya.
}

\begin{abstract}
ABSTRAK
Kinerja karyawan dari PT. Dempo Laser Metalindo Surabaya dipengaruhi oleh sejumlah faktor yang dapat dilihat secara bersama-sama yang melibatkan berbagai fakor, yaitu gaya kepemimpinan, kepuasan kerja, dan kompensasi. Permasalahan yang dihadapi perusahaan adalah keterlambatan kehadiran karyawan dan adanya produk reject dari klien, maka agar tercipta kinerja karyawan yang diharapkan maka perusahaan harus dapat memberikan kompensasi yang sesuai serta gaya kepemimpinan yang bisa mendorong memberikan semangat, sehingga nantinya dapat menimbulkan kepuasan kerja karyawan yang berdampak meningkatnya kinerja karyawan. Structural Equation Modeling (SEM) dengan pendekatan PLS merupakan metode analisis yang dapat digunakan untuk mengetahui pengaruh gaya kepemimpinan terhadap kepuasan kerja, gaya kepemimpinan terhadap kinerja dan kompensasi terhadap kepuasan kerja, kompensasi terhadap kinerja karyawan PT Dempo Laser Metalindo Surabaya. Obyek dari penelitian ini adalah karyawan PT Dempo Laser Metalindo Surabaya, dengan jumlah sampel sebesar 50. Data diperoleh dengan menggunakan kuesioner dan hasil penelitian menunjukkan bahwa gaya kepemimpinan berpengaruh terhadap kepuasan kerja , gaya kepemimpinan berpengaruh terhadap kinerja dan kompensasi berpengaruh terhadap kepuasan kerja, kompensasi berpengaruh terhadap kinerja karyawan PT Dempo Laser Metalindo.
\end{abstract}

Kata Kunci : SEM-PLS, Gaya Kepemimpinan, Kompensasi, Kepuasan Kerja, Kinerja Karyawan

\section{Pendahuluan}

Penelitian ini dilakukan pada PT. Dempo Laser Metalindo Surabaya yang merupakan salah satu perusahaan bergerak di bidang industri fabrikasi sheet metal. Dalam mewujudkan visi dan misi perusahaan, maka sangatlah dibutuhkan cara untuk meningkatkan kinerja karyawan, mengingat perusahaan menggunakan sistem job order, dimana karyawan dituntut untuk menyelesaikan pekerjaan sesuai pesanaan klien, oleh karena itu karyawan membutuhkan ketelitian yang tinggi sehingga tidak akan mengecewakan klien.

Kinerja pada dasarnya adalah suatu hasil kerja yang dicapai seorang dalam melaksanakan tugas-tugas yang dibebankan kepadanya yang didasarkan atas kecakapan, pengalaman dan kesungguhan serta waktu. Karyawan yang puas terhadap pekerjaannya akan cenderung memiliki kinerja yang tinggi pula. Agar tercipta kinerja karyawan yang diharapkan maka perusahaan harus dapat memberikan kompensasi yang sesuai serta gaya kepemimpinan yang bisa 
mendorong memberikan semangat, sehingga nantinya dapat menimbulkan kepuasan kerja karyawan yang berdampak meningkatnya kinerja karyawan. Berikut merupakan data permasalahan absensi karyawan pada divisi Produksi yang terdiri dari empat indikator yaitu, Keterlambatan, Ijin, Cuti, dan Sakit :

Tabel 1. Prosentase Tingkat Absensi karyawan Produksi Jan - Nov 2014

\begin{tabular}{|c|c|c|c|c|c|c|c|c|c|}
\hline Bulan & $|a n-14|$ & Feb-14 & Marr:14 & App 14 & Mei-14 & Jun:-14 & |u|:-14 Agfust:-14| & Sep -14 & Okt:-14 \\
\hline Prosentase Keterlambatan & $20 \%$ & $22 \%$ & $24 \%$ & $27 \%$ & $23 \%$ & $30 \%$ & $20 \%$ & $24 \%$ & $23 \%$ \\
\hline
\end{tabular}

Sumber : Data Kepegawaian PT. Dempo Laser Metalindo

Pada Tabel 1 Menunjukkan bahwa prosentase keterlambatan hadir ratarata setiap bulan selama satu tahun karyawan pada divisi Produksi di PT. Dempo Laser Metalindo, dan sebetulnya perusahaan tidak memberikan toleransi pada keterlambatan, maka perlu bagi pimpinan untuk mencari permasalahan apa yang terjadi dan bagaimana cara memberikan semangat dan dorongan kepada karyawan untuk meningkatkan kepuasan kerja. Dari ketidak disiplinan itu dapat berakibat kepada turunnya kinerja karyawan. Produk reject dari klien, dapat dijadikan indikasi bahwa terdapat penurunan kinerja dari karyawan. Berikut merupakan data reject produk PT. Dempo Laser Metalindo :

Tabel 2. Jumlah Produk (Unit) Reject Jan - Nov 2014

\begin{tabular}{|l|c|c|c|c|c|c|c|c|c|c|c|}
\hline Bulan & Jan-14 & Feb-14 & Mar-14 & Apr-14 & Mei-14 & Jun-14 & Jul-14 & Agust-14 & Sep-14 & Okt-14 & Nop-14 \\
\hline Jumlan Pengiriman & 30 & 15 & 13 & 27 & 37 & 43 & 47 & 17 & 32 & 20 & 50 \\
\hline Jumlah Reject & 5 & 4 & 5 & 2 & 3 & 3 & 6 & 2 & 6 & 5 & 5 \\
\hline
\end{tabular}

Sumber : Data Produksi PT. Dempo Laser Metalindo

Tabel 2 menunjukkan jumlah rata-rata reject hampir $10 \%$ dari total pengiriman tiap bulan dan toleransi dari produk reject yang diterapkan oleh perusahaan hanya $2 \%$ dari total pengiriman, sedangkan pada tabel diatas mayoritas, produk reject lebih dari $2 \%$, maka dari pihak manajemen harus segera melakukan perbaikkan, sehingga bisa mengurangi tingkat produk yang reject.

Structural Equation Modeling (SEM) merupakan suatu teknik analisis statistika yang memiliki kemampuan menganalisis pola hubungan antara variabel laten dan indikatornya. SEM dengan pendekatan Partial Least Square (PLS) merupakan metode analisis yang powerful, karena tidak membutuhkan banyak asumsi dan ukuran sampel tidak harus besar. PLS juga dapat digunakan ketika landasan teori model adalah tentative atau penggukuran setiap variabel laten masih baru, sehingga didesain untuk tujuan prediksi (Vinzi dkk, 2010). Model dalam PLS meliputi tiga tahap, yaitu outer model atau model pengukuran, inner model atau model struktural dan weight relation dimana nilai dari variabel laten dapat diestimasi.

Berdasarkan uraian diatas, maka dilakukan penelitian menggunakan SEM PLS dengan pendekatan PLS dalam membentuk model struktural yang diterapkan pada kasus kinerja karyawan, dimana variabel laten endogen yang digunakana adalah kinerja karyawan, dan variabel laten eksogen yang berpengaruh terhadap variabel endogen antara gaya kepemimpinan, kepuasan kerja dan kompensasi. 


\section{Kerangka Pemikiran dan Hipotesis}

Berdasarkan tinjauan dari telaah pustaka, dapat dibuat kerangka pemikiran teoritis tentang faktor-faktor yang berpengaruh terhadap kinerja karyawan. Kerangka pemikiran penelitian ini dapat dilihat pada Gambar 2.1.

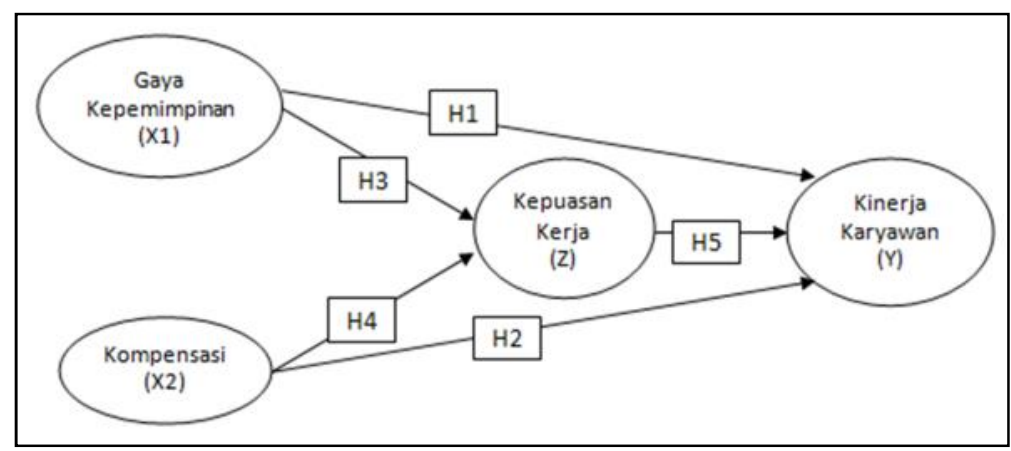

Gambar 2.1. Kerangka Pemikiran

H1: Gaya Kepemimpinan berpengaruh signifikan (positif) terhadap Kinerja Karyawan PT. Dempo Laser Metalindo.

H2: Kompensasi berpengaruh signifikan (positif) terhadap Kinerja Karyawan PT. Dempo Laser Metalindo.

H3: Gaya Kepemimpinan berpengaruh signifikan (positif) terhadap Kepuasan Kerja PT. Dempo Laser Metalindo.

H4: Kompensasi berpengaruh signifikan (positif) terhadap Kinerja Karyawan PT. Dempo Laser Metalindo.

H5: Kepuasan Kerja berpengaruh signifikan (positif) terhadap Kinerja Karyawan PT. Dempo Laser Metalindo.

\section{Metode Penelitian}

Variabel dalam penelitian ini adalah :

1. Gaya Kepemimpinan (variabel bebas)

Merupakan suatu proses mempengaruhi perilaku orang lain agar berperilaku seperti yang akan dikehendaki, Robert House dalam Nugraha, I G.A.D.P (2011).

2. Kompensasi (variabel bebas)

Merupakan kebijakan dari pihak manajemen untuk memberikan segala sesuatu yang diterima oleh karyawan sebagai balas jasa atas upaya-upaya yang telah diberikan kepada perusahaan, menurut Leap dan Crino, (1993) dalam Nalendra, E., (2008).

3. Kepuasan Kerja (variabel intervening)

merupakan keadaan emosional yang menyenangkan atau tidak menyenangkan dimana para pekerja memandang pekerjaannya. Indikator variabel Kepuasan Kerja Menurut Durham, et al., (1997) dalam Lamanto, S.L., (2012).

4. Kinerja Karyawan (variabel terikat) merupakan hasil kerja yang dicapai oleh seseorang dalam melaksanakan tugas yang diberikan kepadanya sesuai dengan kriteria yang ditetapkan. Chester I. Barnard dan Robert E. Quinn dalam Dewi, S.P., (2012). 


\section{Populasi dan Sampel}

Populasi penelitian ini adalah finit dan jumlah karyawan produksi PT. Dempo Laser Metalindo di Surabaya atau elemen populasi relatif sedikit (50 karyawan), maka digunakan metode sensus.

\section{Hasil Analisis dan Pembahasan Validitas Variabel}

Pengujian terhadap model pengukuran adalah dengan melihat nilai AVE (Average Variance Extracted), yaitu nilai yang menunjukkan besarnya varian indikator yang mampu dikandung oleh variabel latennya. Nilai AVE lebih besar 0,5 juga menunjukkan kecukupan validitas konvergen yang baik bagi variabel laten. Nilai AVE dapat dilihat pada tabel dibawah :

Tabel 3. Average Variance Extracted (AVE)

\begin{tabular}{|l|c|}
\hline & Average variance extracted (AVE) \\
\hline Gaya Kepemimpinan & 0.729 \\
\hline Kompensasi & \\
\hline Kepuasan Kerja & 0.732 \\
\hline Kinerja Karyawan & \\
\hline
\end{tabular}

Dari tabel diatas variabel gaya kepemimpinan dan kinerja karyawan memiliki nilai AVE diatas nilai 0.5, berarti variabel tersebut valid.

\section{Reliabilitas}

Reliabilitas konstruk diukur dengan nilai composite reliability, konstruk reliabel jika nilai composite reliability di atas 0,70 indikator dikatakan konsisten dalam mengukur variabel latennya.

Tabel 4. Composite Reliability

\begin{tabular}{|l|c|}
\hline & Composite Reliability \\
\hline Gaya kepemimpinan & 0.915 \\
\hline Kompensasi & \\
\hline Kepuasan Kerja & \\
\hline Kinerja Karyawan & 0.890 \\
\hline
\end{tabular}

Sumber : Data diolah

Hasil pengujian menunjukkan bahwa konstruk (variabel) Gaya Kepemimpinan, Kinerja Karyawan adalah reliabel dengan nilai composite reliability lebih besar dari 0,7 . 


\section{Uji goodness-fit model}

R-Square merupakan uji goodness-fit model. Pengujian inner model dapat dilihat dari nilai $R$-square pada persamaan antar variabel latent. Nilai $R^{2}$ menjelaskan seberapa besar variabel eksogen (independen/bebas) pada model mampu menerangkan variabel endogen (dependen/terikat).

Tabel 5. R-square

\begin{tabular}{|l|l|}
\hline & R-square \\
\hline Gaya Kepemimpinan & \\
\hline Kompensasi & \\
\hline Kepuasan Kerja & 0.523 \\
\hline Kinerja Karyawan & 0.059 \\
\hline \multicolumn{2}{|l}{ Sumber : Data diolah }
\end{tabular}

Nilai $\mathrm{R}^{2}=1-(1-0,523)(1-0,059)=0,4488$, artinya bahwa model mampu menjelaskan fenomena Kinerja Karyawan sebesar 44,88\%. Sedangkan sisanya 55,12\% dijelaskan oleh variabel lain (selain Gaya Kepemimpinan, Kompensasi, dan Kepuasan Kerja) yang belum masuk ke dalam model, seperti motivasi, komitmen organisasi, loyalitas dan variable lainnya.

\section{Uji Kausalitas (inner model)}

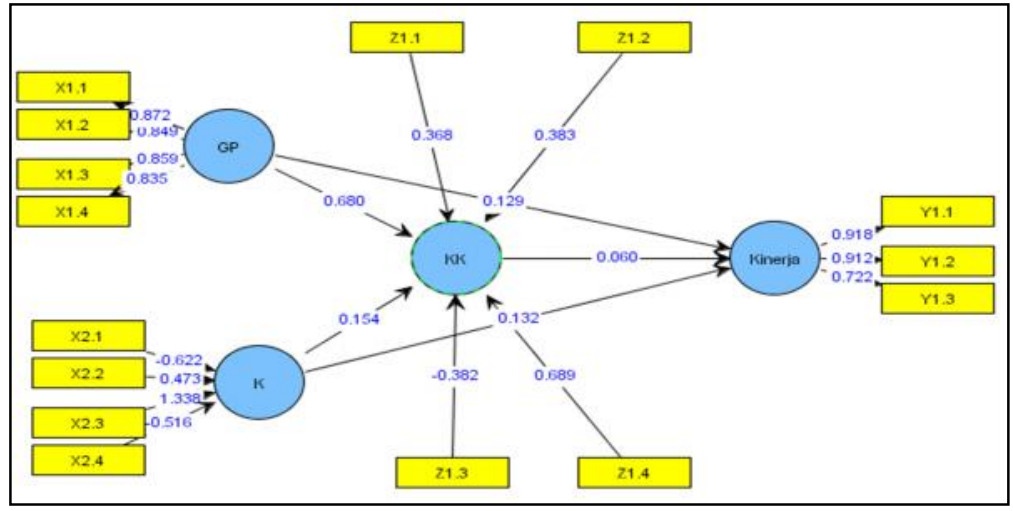

Gambar 2.2 Model Hasil PLS

Tabel 6. Hasil Uji Kausalitas

\begin{tabular}{|l|c|c|c|c|}
\hline & $\begin{array}{c}\text { Koefisien } \\
\text { Path }\end{array}$ & $\begin{array}{c}\text { mean of } \\
\text { subsamples }\end{array}$ & $\begin{array}{c}\text { Standard } \\
\text { deviation }\end{array}$ & $\begin{array}{c}\text { T- } \\
\text { Statistic }\end{array}$ \\
\hline $\begin{array}{l}\text { Gaya Kepemimpinan -> } \\
\text { Kepuasan Kerja }\end{array}$ & 0.680 & 0.680 & 0.018 & 38.647 \\
\hline $\begin{array}{l}\text { K ompensasi -> Kepuasan } \\
\text { Kerja }\end{array}$ & 0.154 & 0.156 & 0.028 & 5.484 \\
\hline $\begin{array}{l}\text { Gaya Kepemimpinan -> } \\
\text { Kinerja Karyawan }\end{array}$ & 0.129 & 0.126 & 0.046 & 2.804 \\
\hline $\begin{array}{l}\text { Kompensasi -> Kinerja } \\
\text { Karyawan }\end{array}$ & 0.132 & 0.130 & 0.020 & 6.651 \\
\hline $\begin{array}{l}\text { Kepuasan Kerja -> Kinerja } \\
\text { Karyawan }\end{array}$ & 0.060 & 0.070 & 0.022 & 2.727 \\
\hline
\end{tabular}


Keterangan:

GP : Gaya Kepemimpinan

K : Kompensasi

KK : Kepuasan Kerja

Kinerja : Kinerja Karyawan

H1 : Gaya Kepemimpinan berpengaruh signifikan positif terhadap kinerja karyawan

Parameter estimasi untuk pengujian pengaruh gaya kepemimpinan terhadap kinerja karyawan menunjukkan bahwa Gaya Kepemimpinan (X1) berpengaruh terhadap Kinerja Karyawan (Y) dengan koefisien path sebesar 0,129, dapat diterima karena nilai $\mathrm{T}$-Statistik $=2,804$ lebih besar dari nilai $\mathrm{Z} \alpha=0,05(5 \%)=$ 1,96 , maka Signifikan (positif) sehingga hipotesis 1 diterima. Dimana artinya jika gaya kepemimpinan mengalami peningkatan maka kinerja dari karyawan akan mengalami peningkatan, Begitu juga sebaliknya jika gaya kepemimpinan mengalami penuruan maka kinerja dari karyawan mengalami penurunan.

H2 : Kompensasi berpengaruh signifikan positif terhadap kinerja karyawan.

Parameter estimasi untuk pengujian pengaruh kompensasi terhadap kinerja karyawan yang menunjukkan bahwa Kompensasi (X2) berpengaruh terhadap Kinerja Kerja (Y) dengan koefisien path sebesar 0,132, dapat diterima karena nilai T-Statistik $=6,651$ lebih besar dari nilai $\mathrm{Z} \alpha=0,05(5 \%)=1,96$, maka Signifikan (positif) sehingga hipotesis 2 diterima. Dimana artinya jika kompensasi mengalami peningkatan maka kinerja dari karyawan akan mengalami peningkatan, Begitu juga sebaliknya jika kompensasi mengalami penuruan maka kinerja dari karyawan mengalami penurunan.

H3 : Gaya Kepemimpinan berpengaruh signifikan positif terhadap kepuasan kerja

Parameter estimasi untuk pengujian pengaruh Gaya Kepemimpinan (X1) terhadap Kepuasan Kerja (Y) memiliki nilai koefisien path sebesar 0.680, dapat diterima karena nilai $\mathrm{T}$-Statistik $=38,647$ lebih besar dari nilai $\mathrm{Z} \alpha=0,05(5 \%)=$ 1,96, maka signifikan (positif) sehingga hipotesis 3 diterima. Dimana artinya jika gaya kepemimpinan mengalami peningkatan maka kepuasan kerja akan mengalami peningkatan, Begitu juga sebaliknya jika gaya kepemimpinan mengalami penuruan maka kepuasan kerja mengalami penurunan.

H4 : Kompensasi berpengaruh signifikan positif terhadap Kepuasan Kerja

Parameter estimasi untuk pengujian Kompensasi (X2) berpengaruh terhadap Kepuasan Kerja (Z) memiliki nilai koefisien path sebesar 0.154, dapat diterima karena nilai T-Statistik $=5,484$ lebih besar dari nilai $\mathrm{Z} \alpha=0,05(5 \%)=1,96$, maka signifikan (positif) sehingga hipotesis 4 diterima. Dimana artinya jika kompensasi mengalami peningkatan maka kepuasan kerja akan mengalami peningkatan, Begitu juga sebaliknya jika kompensasi mengalami penuruan maka kepuasan kerja mengalami penurunan.

\section{H5 : Kepuasan Kerja berpengaruh signifikan positif terhadap Kinerja}

\section{Karyawan}

Parameter estimasi untuk pengujian Kepuasan Kerja ( $Z$ ) berpengaruh terhadap Kinerja Karyawan (Y) memiliki nilai koefisien path sebesar 0.060, dapat diterima karena nilai $\mathrm{T}$-Statistik $=2,727$ lebih besar dari nilai $\mathrm{Z} \alpha=0,05(5 \%)=$ 1,96, maka signifikan (positif) sehingga hipotesis 5 diterima. 
Dimana artinya jika kepuasan kerja mengalami peningkatan maka kinerja dari karyawan akan mengalami peningkatan, Begitu juga sebaliknya jika kepuasan kerja mengalami penuruan maka kinerja dari karyawan mengalami penurunan.

\section{Simpulan dan Saran}

Berdasarkan hasil pengujian hipotesis dan pembahasan, maka dapat dirumuskan beberapa kesimpulan sebagai berikut :

1. Gaya Kepemimpinan mampu meningkatkan Kinerja Karyawan sehingga ini menunjukkan bahwa semakin bagus gaya kepemimpinan yang dirasakan karyawan maka semakin tinggi pula kinerja karyawan, begitu juga sebaliknya semakin rendah gaya kepemimpinan maka semakin rendah kinerja karyawan.

2. Kompensasi mampu meningkatkan Kinerja Karyawan sehingga hasil ini menunjukkan bahwa semakin tinggi kompensasi yang dirasakan karyawan maka semakin tinggi pula kinerja karyawan, begitu juga sebaliknya semakin rendah kompensasi maka semakin rendah kinerja karyawan.

3. Gaya Kepemimpinan mampu meningkatkan Kepuasan Kerja sehingga hasil ini menunjukkan bahwa semakin bagus gaya kepemimpinan yang dirasakan, bisa memberikan kepuasan karyawan dalam bekerja, begitu juga sebaliknya semakin rendah gaya kepemimpinan maka semakin rendah kepuasan kerja karyawan.

4. Kompensasi mampu meningkatkan Kepuasan Kerja sehingga hasil ini menunjukkan bahwa kompensasi yang dirasakan sudah sesuai dengan keinginan karyawan, maka akan memberikan kepuasan karyawan dalam bekerja, begitu juga sebaliknya bila kompensasi dirasa kurang oleh karyawan, maka kepuasan kerja karyawan akan menurun.

5. Kepuasan Kerja mampu meningkatkan Kinerja Karaywan sehingga hasil ini menunjukkan bahwa jika karyawan sudah merasakan kepuasan kerja dengan sendirinya kinerja dari karyawan akan mengalami peningkatan, karena karyawan yang bekerja sudah merasakan kenyamanan dalam bekerja.

\section{Saran}

Sebaiknya pimpinan dalam PT. Dempo Laser Metalindo memperhatikan kinerja karyawan dengan cara meningkatkan gaya kepemimpinan yang bekerja sama dengan bawahan dalam menyusun tugasnya dan memberikan instruksi dalam bekerja, sehingga nantinya diharapkan karyawan akan efektif dan efisien dalam bekerja.

Pada PT. Dempo Laser Metalindo agar ada lebih memperhatikan dalam hal meningkatkan kinerja karyawan melalui kompensasi dengan cara memberikan program kesehatan yang sesuai dan adanya promosi dari perusahaan, nantinya karyawan akan merasa diperhatikan dalam bekerja, sehingga nantinya karyawan diharapkan mampu disiplin dalam bekerja. 


\section{Daftar Pustaka}

Anwar Prabu Mangkunegara, 2004, Manajemen Sumber Daya Manusia Perusahaan. Rosda. Bandung.

Armstrong, Michael, 2004. Performance management (alih bahasa: Tony Setiawan). Yogyakarta : Tugu.

Armstrong, et.al. 1998. Performance Management. London : Institute of Personnel and Development.

Baihaqi, M.F., 2010. Pengaruh Gaya Kepemimpinan Terhadap Kepuasan Kerja dan Kinerja dengan Komitmen Organisasi sebagai Variabel Intervening. Universitas Diponegoro, Semarang.

Baltaci, et.al., 2012. The Effects of Leadership On Job Satisfaction (Visionary Leadership, Transformational Leadership, Transactional Leadership). $3^{\mathrm{rd}}$ International Symposium on Sustainable Development. 2012. 220 - 226.

Ciptani, M.K., 2000. Balanced Scorecard Sebagai Pengukuran Kinerja Masa Depan. Jurnal Akuntansi \& Keuangan. Vol. 2, (1), 21 - 35.

Dewi, S.P., 2012. Pengaruh Pengendalian Internal dan Gaya Kepemimpinan Terhadap Kinerja Karyawan SPBU Yogyakarta. Jurnal Nominal, Vol 1 (1).

Desseler, Gery. 2002. Manajemen Personalia. Alih Bahasa : Agus Dharma, Erlangga, Jakarta

Engko, C., 2008. Pengaruh Kepuasan Kerja Terhadap Kinerja Individual Dengan Self Esteem dan Self Efficacy Sebagai Variabel Intervening. Jurnal Bisnis dan Akuntansi, Vol. 10 (1), 1 -12.

Fitriyah, H., 2013. Analisis Kinerja Pegawai BPKAD Provinsi Jawa Timur. Tugas Akhir Program Magister. UPN Veteran Jawa Timur.

Gibson, et.al. (2012). Organizations. New York : McGraw-Hill.

Hidayat, R., 2013. Pengaruh Kepemimpinan terhadap Komunikasi, Kepuasan Kerja, dan Komitmen Organisasi pada Industri Perbankan. Makara Seri Sosial Humaniora, 2013, 19 - 32.

Irbayuni, S., 2012. Pengaruh Kompensasi, Kepuasan Kerja, Dan Komitmen Organisasi Terhadap Keinginan Untuk Pindah Kerja Pada PT. Surya Sumber Daya Energi Surabaya. jurnal NeO-Bis, Vol. 6, No. 1, Juni 2012.

Indrawati, A.D., 2013. Pengaruh Kepuasan Kerja Terhadap Kinerja Karyawan dan Kepuasan Pelanggan pada Rumah Sakit Swasta di Kota Denpasar. Jurnal Manajemen, Strategi Bisnis, dan Kewirausahaan, Vol. 7 (2), 135 142.

Keith, Davis, Jhon W. Newstrom. 1995. Perilaku Dalam Organisasi, Edisi ketujuh. Jakarta : Erlangga

Kirkpatrick, Shelley A., 2011. Visionary Leadership Theory. Encyclopedia of Leadership. 2004.

Kirkpatrick, Donald, L., 2006. Improving Employee Performance. New York : Amacom.

Lestari, D.A., 2006. Penciptaan Sistem Penilaian Kinerja yang Efektif Dengan Assessment Centre. Jurnal Manajemen, Vol. 6 (1), 23 - 34. 
Lamanto, S.L., 2012. Pengaruh Gaya Kepemimpinan Terhadap Kepuasan Kerja Dengan Moderasi Locus Of Control Dan Kejelasan Tugas Pada Peran Auditor Yunior. Jurnal Ilmiah Mahasiswa Akuntasi, Vol. 1 - No. 1, Januari 2012, $21-25$.

Lohmoller, J.B., 1989. Latent Variable Path Modeling With Partial Least Squares. Spinger - Verlag Berlin Heidelberg.

Mahesa, D., 2010. Analisis Pengaruh Motivasi dan Kepuasan Kerja Terhadap Kinerja Karyawan Dengan Lama Kerja Sebagai Variabel Moderating. Universitas Diponegoro, Semarang.

Mangkunegara, AP. 2000. Manajemen Sumber Daya Manusia. Bandung : Rosda

Nalendra, E., 2008. Pengaruh Kompensasi dan Motivasi Kerja Terhadap Kepuasan Kerja Karyawan Pada PT. Karya Sedati Vidyatama. Universitas Katolik Soegijapranata, Semarang.

Nugraha, A.D.P., 2011. Pengaruh Gaya Kepemimpinan Dan Motivasi Kerja Terhadap Kepuasan Kerja Anggota Detasemen C Satuan III Pelopor Korps Brimob Polri. Tesis. Universitas Indonesia.

Nugroho, A.D., Kurnatinah., 2012. Analisis Pengaruh Kompensasi dan Pengembangan Karier Terhadap Kepuasan Kerja dengan Mediasi Motivasi Kerja. Jurnal Bisnis dan Ekonomi (JBE). Vol. 19 (2), 153 - 169.

Nuswandari, C., 2009. Pengaruh Corporate Governance Perception Index Terhadap Kinerja Perusahaan Pada Perusahaan Yang Terdaftar di Bursa Efek Jakarta. Jurnal Bisnis dan Ekonomi (JBE), September 2009, 70 - 84.

Raharjo, S.T., Nafisah, D., 2006. Analisis Pengaruh Gaya Kepemimpinan Terhadap Kepuasan Kerja, Komitmen Organisasi Dan Kinerja Karyawan (Studi Empiris Pada Departemen Agama Kabupaten Kendal Dan Departemen Agama Kota Semarang), Jurnal Studi Manajemen \& Organisasi, Vol. 3 - No. 2, Juli 2006, 69 - 81.

Riyadi, S., 2011. Pengaruh Kompensasi Finansial, Gaya Kepemimpinan, dan Motivasi Kerja Terhadap Kinerja Karyawan pada Perusahaan Manufaktur di Jawa Timur. Jurnal Manajemen Dan Kewirausahaan, Vol. 13 - No. 1, Maret 2011, 40 - 45.

Robbins, Stephen P. 1994. Organization Theory, Structure, Design and Application. Alih Bahasa Yusuf Udara, Jakarta : Arean.

Robbins, Stephen P. Dan Mary Coultar, 1996. Management. New Jersey : Prentice Hall, Inc.

Ruvendi, R., 2010. Imbalan dan Gaya Kepemimpinan Pengaruhnya Terhadap Kepuasan Kerja Karyawan di Balai Besar Industri Hasil Pertanian Bogor. Jurnal Ilmiah Binaniaga. Vol. 1 (1), 17 - 26.

Santoso, E., 2006. Pengaruh Kepemimpinan, Motivasi, Kompensasi dan Disiplin Kerja Terhadap Kinerja Karyawan di Bank Central Asia Kudus.

Satyawati, N.M.R., Suartana, I.W., 2014. Pengaruh Gaya Kepemimpinan Dan Budaya Organisasi Terhadap Kepuasn Kerja Yang Berdampak Pada Kinerja Keuangan. E-Jurnal Akuntansi Universitas Udayana 6.1, 2014, 1732.

Setiawan, W., 2009. Peran Kepemimpinan Visioner Untuk Menghasilkan Calon Pendidik Yang Berkarakter Kuat dan Cerdas di Fakultas Keguruan dan Ilmu Pendidikan. UNS, Surakarta. 
24) Stuctural Equation Modeling Partial Least Square (SEM PLS) untuk Mengetahui Kinerja Karyawan Pada PT. DEMPO Laser Metalindo Surabaya

Simanjuntak, P.J., 2011. Manajemen \& Evaluasi Kinerja ( $3^{\text {rd }}$ ed.). Jakarta : F.E. Universitas Indonesia.

Suddin, A., 2012. Pengaruh Kompensasi Terhadap Kepuasan Kerja Karyawan Bank Mega Dengan Motivasi Kerja Sebagai Variabel Moderasi. Jurnal Manajemen Sumber Daya Manusia Vol. 6 (2), 95 - 105.

Susanta, I.W.N., et.al., 2013. Pengaruh Kompensasi dan Kepemimpinan Terhadap Kinerja Karyawan Pada Jasa konstruksi di Denpasar. Jurnal Ilmiah Elektronik Infrastruktur Teknik Sipi. Vol. 2 (2), V-1 - V-8.

Soegihartono, A., 2012. Pengaruh Kepemimpinan dan Kepuasan Kerja Terhadap Kinerja dengan Mediasi Komitmen di PT Alam Kayu Sakti Semarang. Jurnal Mitra Ekonomi dan Manajemen Bisnis, Vol.3, No. 1, April 2012 : $123-140$.

Utomo, S.B., 2010. Pengaruh Motivasi dan Kepuasan Kerja Terhadap Kinerja Karyawan CV. Berkat Cipta Karya Nusantara Surabaya. JAMBSP. Vol. 6 (3), $376-393$.

Wibowo, 2014. Manajemen Kinerja (4 ${ }^{r d}$ ed.). Jakarta : Rajawali Pers.

Yukl, G., 2010. Kepemimpinan Dalam Organisasi ( $5^{\text {rd }}$ ed.). Jakarta : PT. Indeks (Original Work Publish 2001).

. 2014. Analisis Model Struktural Model indikator Refleksif \& Formatif. "kumpulan Tulisan Drs. Ec. Indro Kirono, MM". Power Point tidak diterbitkan. Surabaya. 